\title{
The effect of STEM education roles on the solution of daily life problems
}

\begin{tabular}{|c|c|}
\hline \multicolumn{2}{|c|}{ Child Development Department, University of Muş Alparslan, Muş, Turkey } \\
\hline Article history & The main purpose of this research is to determine the effect of STEM \\
\hline $\begin{array}{l}\text { Received: } \\
06.07 .2019\end{array}$ & $\begin{array}{l}\text { roles on the solutions to daily life problems and academic achievement. } \\
\text { Mixed method was used in the study. An experimental study was }\end{array}$ \\
\hline $\begin{array}{l}\text { Received in revised form: } \\
18.09 .2019\end{array}$ & $\begin{array}{l}\text { conducted in the quantitative dimension of the research, while a fully } \\
\text { structured STEM activity form was used in the qualitative dimension. } 38 \\
\text { students participated in the study by analogue sampling method. STEM }\end{array}$ \\
\hline $\begin{array}{l}\text { Accepted: } \\
26.09 .2019\end{array}$ & $\begin{array}{l}\text { roles brochure, STEM roles activity form and academic achievement test } \\
\text { were used in the research. The data of the measurement tools used in the }\end{array}$ \\
\hline Key & study were analyzed with the help of Microsoft Excel program and SPSS. \\
\hline $\begin{array}{l}\text { Academic achievement; Daily } \\
\text { life problems; Science; STEM } \\
\text { education; STEM roles; }\end{array}$ & $\begin{array}{l}\text { Descriptive and content analyses and techniques such as Mann-Whitney } \\
\text { U Test and percentage values were used. It was determined that STEM } \\
\text { disciplines and STEM roles had a significant effect on the solutions to } \\
\text { daily life problems. For instance, it was found that participants lifted the } \\
\text { stone in the middle of the field with a lever which was section (meters) } \\
\text { and removed the elephant using pulley, depending on the number of } \\
\text { ropes. It was determined that the participants lifted a lot of load by } \\
\text { applying less force. Yet, it was determined that STEM roles did not have } \\
\text { any effect on increasing academic achievement according to the current } \\
\text { curriculum. In line with these results, suggestions were presented. }\end{array}$ \\
\hline
\end{tabular}

\section{Introduction}

The need for new educational approaches has emerged in the developing and growing world. These training needs arise mainly from countries' economic development plans and qualified staff training (West, 2012). Today, the concept of quality is given priority in fulfilling the social roles of the individual. The individual's self-development in many respects has taken a role amongst the educational objectives of the countries. The quality of the individual is defined as the successful execution of his / her profession in every aspect (Demirkuş, 2019; MoNE, 2018). It is assumed that individuals acquire qualifications through their education in educational settings. As a matter of fact, the effect of the family is as great as the school in this education. One of the new educational goals is to design education in and out of schools in a way that can highlight the characteristics of individuals (Olson and Labov, 2014). Especially in the fields of science, technology, engineering and mathematics, the training of the individual or the training provided within the scope of these disciplines is one of the primary objectives. That is why STEM education, which has become a trend all over the world, is known as the qualifying approach of today (Çepni, 2018).

The National Science Foundation (NSF-United States) used the concept of SMET (science- 
mathematics-engineering-technology) in the 90s, which turned out to be STEM (sciencetechnology- engineering-mathematics) in 2000s (Sanders, 2009). Especially after 2007, STEM education institutions began to appear. Later on, STEM education approach emerged with the developing studies (Johnson, 2012). STEM education approach is linked to the decrease in the interest of individuals in professions, inequality between women and men in acquiring profession, economic targets due to the increasing industry and competition market and increasing the number of qualified individuals. In addition, it is thought that individuals who grow up with STEM education will be more objective in any social or personal preferences that may affect their country's future (Gülen and Yaman, 2019). In addition, it is assumed that individuals will gain the ability to solve the problems they encounter in daily life through STEM education (Gülen, 2018).

STEM education increases the development of socio, cognitive and psycho-motor aspects of the individual. In fact, the individual gains technical and social skills such as research, learning and questioning, problem solving, observation, experiment, presentation and other business applications. It also develops analytical, logical, critical, systematic, structured, questioning, evaluative, independent, reasoning, skeptical, evidence-based, rational, openminded, innovative, creative thinking. In addition, through the scientific method, individuals gain STEM subject knowledge, basic STEM knowledge and learn about the words of STEM (West, 2012). All these skills help the individual to solve the problems they face in their daily life. Similarly, besides being effective in solving the daily life problems of the individual, these help individuals recognize the STEM professions and assume the roles of these professions (Carnevale, Smith and Melton, 2011).

From an early age onwards, it is important for an individual to become a professional or to recognize a profession. The harmony of the individual's future profession and abilities increases the sustainability of STEM professions (Rosenhal, London, Levy, and Lobel, 2011). As a matter of fact, the individual continues the profession where he / she has more compatibility or less conflict between two or more identities (Roccas and Brewer 2002). Among all these, an individual need to be familiar with STEM disciplines, learn STEM professions and develop role models appropriate to these professions. Indeed, it is known that; the role of STEM professions in economic competition and in the continuous renewal race (West, 2012) is tremendous. The jobs that people do, the food they eat, the vehicles by which they travel, the information they receive, the drugs they resort to, and many other aspects of modern life, are constantly changing as the STEM gains knowledge and so do the STEM occupational roles (Olson and Labov, 2014).

It is thought that students are not fully aware of or have internalized STEM disciplines as desired (Breiner, Harkness, Johnson and Koehler, 2012; Maltese and Tai, 2011) and that they cannot use role models of these disciplines because they do not know the professions sufficiently (Gülen and Yaman, 2018; Osborne, Simon, and Collins, 2003). To that end first of all, STEM education activities should be enhanced in science courses. In addition, students are required to recognize the STEM disciplines and develop role models for these disciplines. For this reason, in this study, the effect of STEM roles acquired by the recognition of STEM disciplines on the solutions to daily life problems was investigated. It is also aimed to determine the effect of STEM roles on academic achievement. 


\section{Purpose of the research}

The main purpose of this research is to determine the effect of STEM roles on the solutions to daily life problems and academic achievement. For this purpose, the answers of the following questions were sought.

(1) What is the role of STEM disciplines in solving daily life problems?

(2) How did the participants use the STEM roles activity form?

(3) Is there a significant difference in the effect of STEM roles on academic achievement according to pre-post-test data?

\section{Method}

Mixed method was used in the study. With this method, it is aimed to complement the qualitative and quantitative data (Creswell, 2017). The document was analyzed in qualitative aspects of the study. The aim of the document analysis is to support quantitative data by analyzing fully structured STEM roles activity form documents used by the participants throughout the research (Yıldırım and Şimşek, 2013). Experimental design (true experimental designs) with experimental and control groups was preferred in the quantitative part of the study. Experimental study enables to see how effective a particular intervention will be in solving a particular problem under controlled conditions. Experimental and control groups were randomly selected as part of the design of the study (Büyüköztürk, 2009; Çepni, 2010; Metin, 2014). In this study, simple machines among the 8th grade subjects of science were discussed. STEM roles activities were used in addition to the experimental group's existing instructional processes while the control group was trained according solely to the current curriculum. In the qualitative aspect of the study, a fully structured STEM roles activity form containing daily life problems was used to examine the problem-solving steps of the students in detail. The following steps were used in the study.

\section{Research method application steps}

Determination of objectives and problems: This step is explained above.

Method: Mixed method was used to determine the effect of STEM roles on the solutions to daily life problems and academic achievement.

Determination and preparation of measuring instruments: (1) STEM roles brochure: This course is designed for students to learn the general characteristics of experts in the disciplines of science, technology, engineering and mathematics. Therefore, in the process of structuring information, the teacher provided examples of the general characteristics of these disciplinary experts. These brochures were kept by the students throughout their learning. (2) STEM roles activity form: Prepared for the use of students taking on the roles of experts from the disciplines of science, technology, engineering and mathematics to solve daily life problems. In the research, only two activities were prepared because there were two subjects to be acquired and also due to time constraints. The activities prepared are intended for the use of simple machines in solving daily life problems. The students took on the roles of four disciplines in solving this problem. (3) Academic achievement test: This is a multiple-choice test of seven questions covering simple machines. This test was applied at the beginning and end of the application. It is aimed to determine the effect of STEM roles activities on academic achievement. 
Determination of the groups: Groups were randomly selected as the experimental control groups.

Pretest: Academic achievement test was applied to experimental and control groups.

Application: The application lasted for 3 weeks. In this process, students structured the knowledge about simple machines within the framework of STEM disciplines. Throughout the course, the instructor provided data on the characteristics of STEM disciplines and their perspectives on the problem, along with the subject gains. Under the guidance of their teachers, students structured the knowledge by thinking as experts of STEM disciplines. They also solved the problems of daily life in the given activities. For example, they learned that the wheelbarrow is a simple machine (from the Science expert's perspective). They understood that wheelbarrow is a tool that facilitates daily life (from a Technologist's perspective). They designed and drew the wheelbarrow, and also focused on alternative drawings (from an Engineer's perspective). Finally, they learned the amount of load a wheelbarrow can take in relation to the length of the lever and its effect on lifting the load, the support distance and the effect on force (from a Mathematician's perspective).

Posttest: Academic achievement test was applied to experimental and control groups.

Conclusion: The data obtained as a result of the application is presented in the findings section of the research.

\section{Participants}

Homogeneous (analogous)samples were used in the study. The aim in the analogous sampling is to determine the status of groups of similar characteristics in a subject in order to collect the data effectively (Creswell, 2013). This research was conducted with 8th grade students in a public school in Eastern Anatolia Region during the 2018-2019 academic years. A total number of 38 students participated in the study, voluntarily. The socio-economic status of the participants were similar to each other. The families of the majority of the participants are engaged in farming. Farming here means carrying out small-scale agricultural activities.

\section{Data collection tools}

The STEM roles brochure was used to familiarize participants with STEM disciplines and assist them in adopting STEM roles. Fully structured STEM roles activity form with daily life problems was used in order to solve the relevant problem, to design and perform mathematical operations. Along with that, so as to measure the students' knowledge on the subject, an academic achievement test was conducted with reliability and validity studies.

\section{Analysis of data}

The data of the measurement tools used in the study were analyzed with the help of Microsoft Excel program and SPSS. Descriptive and content analyses and techniques such as Mann-Whitney U Testand percentage values were used. In addition, the scoring criteria in Table 1 were used to describe the STEM roles activity form and to support quantitative data. 
Table 1. STEM roles activity form scoring key

\begin{tabular}{lc}
\hline Criteria & Score \\
\hline $\mathbf{1}$ If left blank & 0 \\
$\mathbf{2}$ If there is incorrect information & 1 \\
$\mathbf{3}$ Misconceptions & 5 \\
$\mathbf{4}$ Any scientifically accepted suggestions \\
4.1. Defining the problem situation (5 points) \\
4.2. Determination of the solution proposal (5 points) \\
4.3. Determination of technological instruments in the solution taking the role of technologists \\
(5 points) \\
4.4. Designing the solution taking the role of an engineer (5 points) \\
4.5. Taking the role of a mathematician to make the necessary calculations in the solution (5 \\
points) \\
4.6. Taking the role of a scientific expert to make the solution proposal through generalizing \\
$\quad$ and gathering information (5 points) \\
4.7. Determination of results in solution (5 points)
\end{tabular}

Table 1 shows the STEM roles activity form scoring criteria. The scores obtained with this scoring were converted to a hundred points. In addition, scoring was realized according to the consistency of scoring of two faculty members.

\section{Reliability and Validity}

Within the scope of the reliability studies, the status of the sample group was explained in detail, the existing roles were explained, the conceptual framework and data collection and analysis were presented. In addition, these data were supported by descriptive analysis and content analysis (Glesne, 2013). Assistance was requested from another faculty member in the preparation and scoring of measurement instruments. Scoring consistency was calculated as $95 \%$. For the coding and scoring, reliability was calculated using the formula of Miles and Huberman (1994). According to this calculation, $87 \%$ confidence coding was performed throughout the study. Miles and Huberman (1994) state $80 \%$ and above acceptable for reliability (Arik and Yilmaz, 2017). In the descriptive and content analysis of validity of the research, direct quotations were given, and the accuracy of the research results was shown (Merriam, 2013). The codes used in the content analysis and the interpretations were done in depth. The names of the participants group are coded. Together with that academic success test questions were selected from the reliability and validity questions. These questions are also included in the student textbook. Although the reliability and validity study had already been performed, it was re-performed during the course of study. The Cronbach Alpha value of the academic achievement test was found to be 0.71 . In addition, as a result of item analysis the item difficulty index of the test was found to be 0.48 (Very good), and the item discrimination index of the test was 0.56 (Very good discrimination). There are seven questions in the academic achievement test. The questions were prepared to cover both gains. These questions are at the level of recall, comprehension and practice. Additionally, the structure and appearance validity of the test was ensured with an expert's opinion. The structure and appearance validity of the test was obtained through expert opinion (Metin, 2014; Yıldırım and Şimşek, 2013).

\section{Findings}

The data obtained in the study are presented below in the order of the research problems. Both qualitative and quantitative analyses were performed to determine the role of 
STEM disciplines in solving daily life problems. Table 2 presents the scores obtained at each step of the form.

Table 2. STEM roles activity form quantitative data

\begin{tabular}{|c|c|c|c|c|c|c|c|c|c|}
\hline \multicolumn{10}{|c|}{ First Problem (Removal of Stone from Field) } \\
\hline Group & Problem & Solving & Science & Technologists & Engineers & Mathematicians & Results & Total & Percent \\
\hline 1 & 5 & 5 & 5 & 5 & 5 & 5 & 5 & 35 & 100 \\
\hline 2 & 5 & 5 & 5 & 5 & 5 & 5 & 5 & 35 & 100 \\
\hline 3 & 5 & 5 & 5 & 5 & 5 & 5 & 5 & 35 & 100 \\
\hline 4 & 5 & 5 & 5 & 5 & 5 & 5 & 5 & 35 & 100 \\
\hline 5 & 5 & 5 & 5 & 5 & 5 & 5 & 5 & 35 & 100 \\
\hline \multicolumn{10}{|c|}{ The Second Problem (Gathering the Elephant in the Car) } \\
\hline Group & Problem & Solving & Science & Technologists & Engineers & Mathematicians & Results & Total & Percent \\
\hline 1 & 5 & 5 & 5 & 5 & 5 & 5 & 5 & 35 & 100 \\
\hline 2 & 5 & 5 & 5 & 5 & 5 & 5 & 5 & 35 & 100 \\
\hline 3 & 5 & 5 & 5 & 5 & 5 & 5 & 5 & 35 & 100 \\
\hline 4 & 5 & 5 & 5 & 5 & 1 & 5 & 5 & 31 & 88.57 \\
\hline 5 & 5 & 5 & 5 & 5 & 5 & 5 & 5 & 35 & 100 \\
\hline
\end{tabular}

Table 2 shows the scores of STEM activity form application steps. Another element that appears here is the ability of the participants to refer to Science, Technology, Engineering and Mathematics knowledge. The role of STEM disciplines appears to be effective in solving daily life problems. In other words, the quantitative values of the roles of a Technologist, Engineer, Mathematician and Science expert appear in the solution of the problem. Accordingly, all STEM roles show great success in both problems. In fact, all roles showed full success $(100 \%)$. It was determined that only the fourth group of mathematicians made a mathematical operation error in the solution of the second problem. This is also stated in the content analysis. The responses of the groups to the STEM roles activity form were discussed in two themes below.

\section{Theme 1. Removing the Stone from the Field}

In this theme, the data of the groups for the removal of 500 Newton of stone in the middle of a farmer's field are discussed.

\section{Category 1. Defining the problem and suggesting a solution}

In this category, it is understood from the following examples that all groups make similar definitions and offer solutions.

Problem: Stone in the middle of the field (Group 3).

Solution: To remove this stone with the help of a lever, but first place a pit under the stone and place this lever (Group3)

Problem: The stone is in the middle (field) and cannot be removed (Group 5).

Solution: Easier to lift and move (Group5).

As it is understood from the quotations above, the groups see that there is a "stone" in the middle of the "field" and that the "removal" and "transportation" of the stone using "leverage" is a solution. It was found that all groups wrote similar answers. In addition, the roles of technology, engineers and mathematics experts of the groups are mentioned below. 


\section{Category 2. Technologist Engineer and Mathematician}

In this category, the approach to the problem according to the roles played by the groups is discussed. The citations obtained in this context are presented below.

Technologist: We will make a simple leverage; we will lift our load using force (Group1).

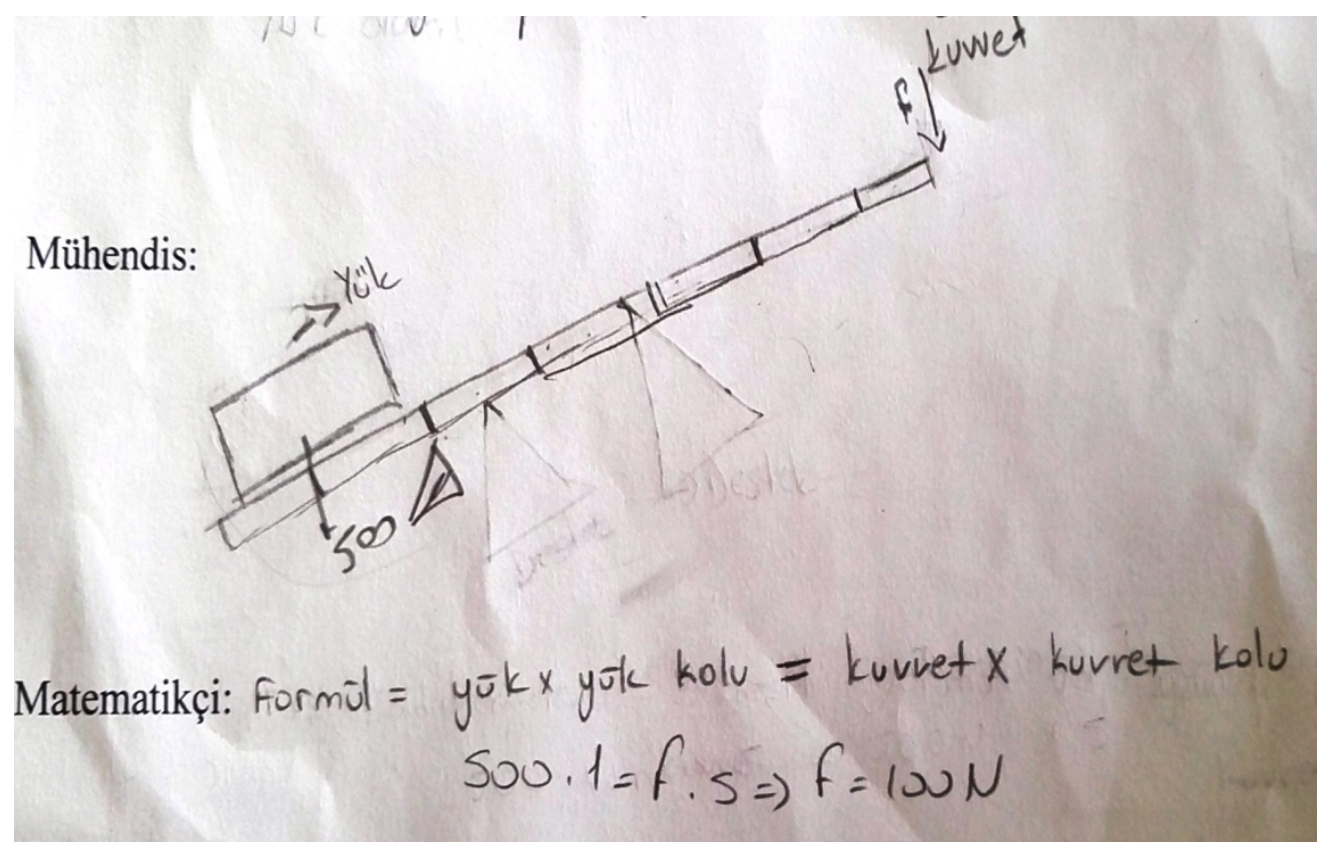

Figure 1. Engineering designs and mathematical calculations of the first group members of Technologist: if a lever is used in the middle of the support, gain is obtained from the force. I used an 11-segment leverage (Group 4).

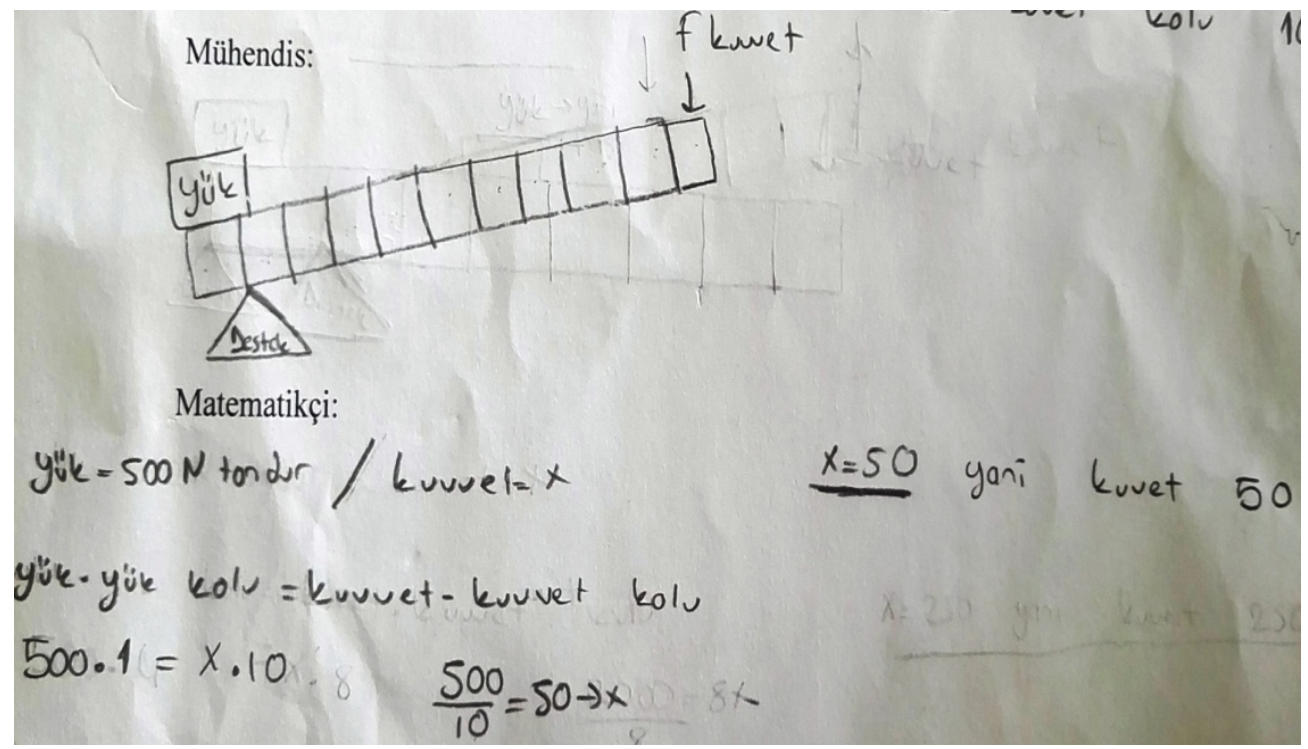

Figure 2. Engineering designs and mathematical calculations of the fourth group members

As can be seen from the above quotations, "technologists" from the group members stated that the "stone" in the middle of the field can be lifted by using a "lever" in certain sections (meters). In addition, as shown in Figures 1 and 2 (similar to other groups), engineers 
designed the drawing of "lever", "support", "load" and "force". Mathematicians have done the necessary "mathematical operations". Accordingly, they determined the minimum "force value" that should be applied by multiplying the "load" and "the load arm" and "the force" and "arm". The most important point to note here is the number of levers used and the mathematical operations. The table obtained in this context is given below.

Table 3. The amount of force to be applied in the first problem (removing the stone from the field)

\begin{tabular}{clc}
\hline Group & System & Force (Newton) \\
\hline 1 & 6 meter lever & 100 \\
2 & 16 meter lever & 33.33 \\
3 & 11 meter lever & 50 \\
4 & 11 meter lever & 50 \\
5 & 11 meter lever & 50 \\
\hline
\end{tabular}

As can be seen in Table 3, the first group applies a 100 Newton force using a 6 meter lever and the second group applies a 33.33 Newton force using a 16 meter lever. The third, fourth and fifth groups stated that they would lift the stone by applying 50 Newton force with 11 meter levers. Generally, it is seen that the second group members apply less force, but the majority applied force with 50 Newton with 11 meter leverage.

\section{Category 3. Result of problem solving}

In this category, science expert quotations and result data are discussed. The excerpts obtained accordingly are presented below.

Scientist: Scientifically we've lifted a lot of load using little force (Group 2).

Conclusion: As a result, we removed the stone with little force (Group 2).

Scientist: This invention works because the mathematicians formulate this stone with little force to displace it (Group 3).

Conclusion: We removed a large stone with little force (Group3).

As can be seen from the above excerpts, it is understood that the "scientific experts" have reached a general "judgment" by combining the "technologist's suggestion", the "design of the engineer" and the "calculations of the mathematician". According to this, they were able tolift a "large load" with a "little force" using a leverage. In addition, it can be said that "all groups" stated this in the conclusion.

\section{Theme 2. Elephant Carriage}

In this theme, the data of the groups that were used to put an elephant that lost 1000 Newton into the car without damage were discussed.

\section{Category 1. Defining the problem and suggesting a solution}

The following examples show that all groups in this category make similar definitions and offer solutions.

Problem: The elephant is lost. This elephant cannot go home. We will try to take this elephant home (Group 4). 
Solution: We can put the elephant in the car with a pulley system without hurting it (Group4)

Problem: The elephant cannot get into the car... (Group 5).

Solution: Ride the elephant into the carriage using the pulley (Group 5).

As it is understood from the above quotations, the groups see the disappearance of the "elephant" and the "inability to get into the car" as a solution for the elimination of the elephant and putting it in the car using the "pulley or pulley system". As a matter of fact, it was found that "all groups" wrote "similar" answers. In addition, technologists, engineers and mathematics expert roles in the groups with the given recommendations stated below

Category 2. Technologist, Engineer and Mathematician

In this category, the approach to the problem according to the roles assumed by the groups is discussed. The citations obtained in this context are presented below.

Technologist: This project we have done is to help the elephant reach the house without being damaged. If we use a leverage, the elephant may be damaged (Groupl).

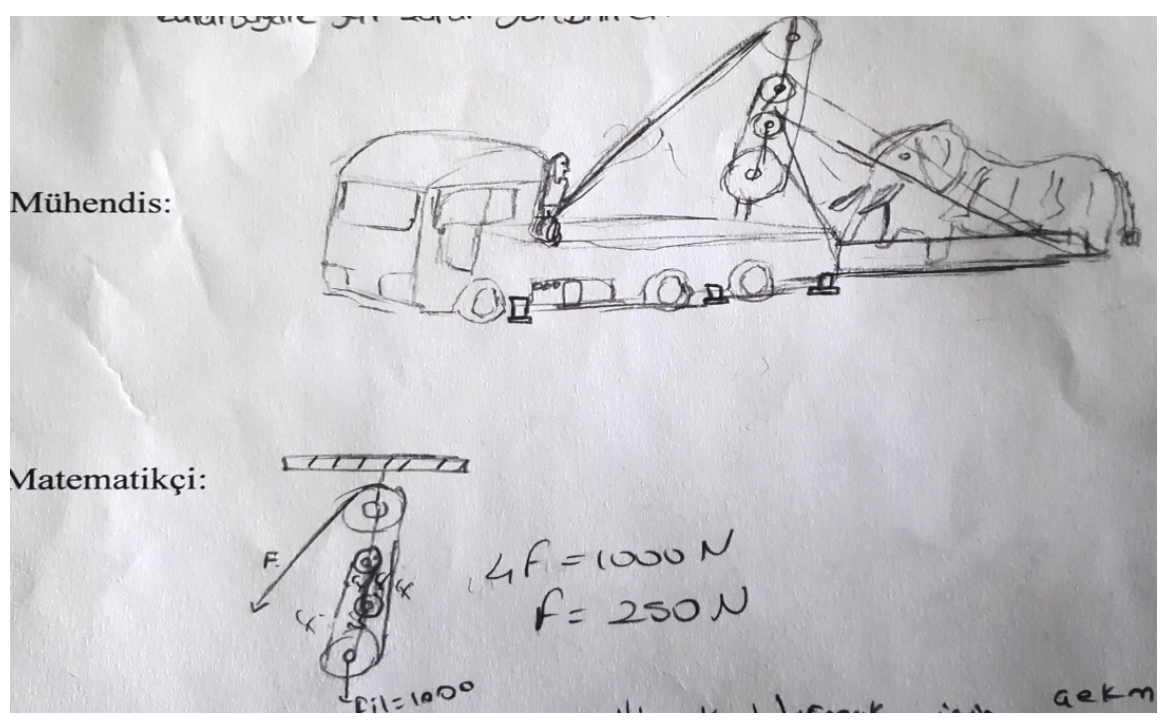

Figure 3. Engineering designs and mathematical calculations of the first group members of Technologist: We can lift the elephant with little force. 


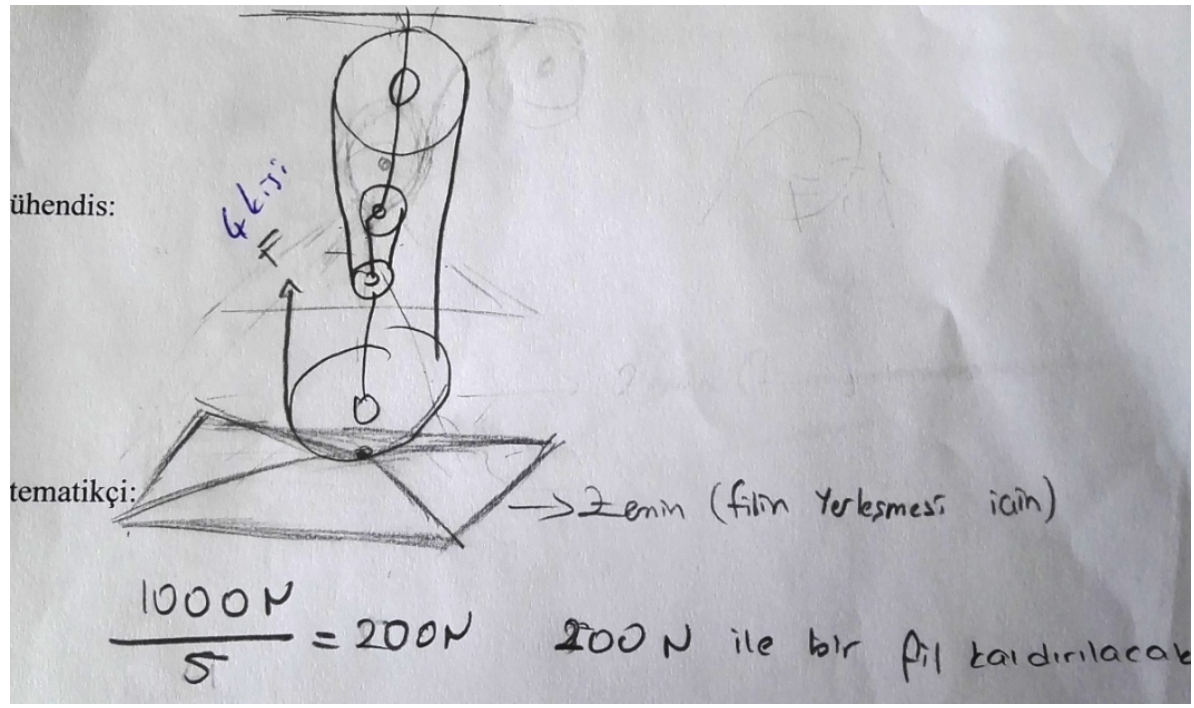

Figure 4. Engineering designs and mathematical calculations of the third group members

As it is understood from the aforementioned quotations, "technologists" from the members of the group stated that the "elephant" can be lifted by using "projects" like "pulley block". In addition, as shown in Figures 1 and 2 (similar to other groups), engineers created "pulley" with "pulley systems" and designed the drawing by specifying the "number of ropes". Mathematicians carried out the necessary "mathematical operations". Accordingly, they determined the "minimum force" value required by "applying" the "load" divided by the "number of ropes". The most important situation to be considered here is the number of ropes and mathematical operations. The table obtained in this context is given below.

Table 4. The amount of force to be applied in the second problem (Elephant lifting)

\begin{tabular}{clc}
\hline Group & System & Force (Newton) \\
\hline 1 & 4-string pulley & 250 \\
2 & 4-string pulley & 250 \\
3 & 5-string pulley & 200 \\
4 & 6-string pulley & 125 \\
5 & 4-string pulley & 250 \\
\hline
\end{tabular}

As shown in Table 4, the first, second and fifth groups applied "250 Newton" using "4-string" pulley, and the fifth group applied "200 Newton" using "5-string" pulley. The fourth group stated that they would lift the stone by applying " 125 Newton" force with "6-string" pulley. But the fourth group made a mathematical error. They applied a force of 166.67 Newton with 6 ropes. In general, the sixth group members determined to apply less force, but the majority applied a force of 250 Newton with a 4-string pulley.

\section{Category 3. Result of problem solving}

In this category, science expert's and result data are discussed. The excerpts obtained accordingly are presented below.

Scientist: Normally we could have lifted the elephant 1000N but using the hoops we lifted $250 \mathrm{~N}$ (Group 2).

Conclusion: As a result, we lifted a lot of load with a small force (Group 2). 
Scientist: Used a pulley and 4 ropes used. Pulling the force down, we lifted the elephant up and put it in the car (Group 5).

Conclusion: Gain from strength. This allows the elephant to be raised more easily and put into the car with little force (Group 5).

As can be seen from the above excerpts, it is understood that the "scientific experts" reached a general "judgment" by combining the "technologist's suggestion", the "design of the engineer" and the "calculations of the mathematician". According to this, they could lifta "large load" using a "little force" by using a leverage. In addition, it would be fair to state that "all groups" stated this in the conclusion

In addition to qualitative findings, quantitative data regarding the academic achievement test applied within the scope of the research are presented below.

Table 3. Academic Achievement Test Mann-Whitney U Test results

\begin{tabular}{|c|c|c|c|c|c|c|c|}
\hline & Groups & $\mathbf{N}$ & Mean Rank & Sum of Ranks & $\mathbf{U}$ & $\mathbf{Z}$ & $\mathbf{p}$ \\
\hline \multirow[t]{2}{*}{ Pretest } & Experimental group & 20 & 19.9 & 398 & \multirow{2}{*}{112} & \multirow{2}{*}{-1.3} & \multirow{2}{*}{0.19} \\
\hline & Control group & 15 & 15.47 & 232 & & & \\
\hline \multirow[t]{2}{*}{ Posttest } & Experimental group & 20 & 21.35 & 427 & \multirow{2}{*}{143} & \multirow{2}{*}{-1.2} & \multirow{2}{*}{0.246} \\
\hline & Control group & 18 & 17.44 & 314 & & & \\
\hline
\end{tabular}

As it is understood in Table 3, there was no significant relationship between the pretest scores of the experimental and control groups since $p=0.19$. In addition, there was no significant relationship between the posttest scores of the experimental and control groups, since $\mathrm{p}=$ 0.246 .

\section{Discussion}

It can be said that STEM disciplines have a high impact on the solution of daily life problems. It is determined that the participants fulfilled the STEM roles that they fully acquired. It is obvious that the use of STEM disciplines in solving daily life problems increases depending on learning. Similarly, Ong, Smith, and Ko (2017) determined that disciplinary diversity in STEM trainings and student roles should be increased. Thusly it would not be wrong to highlight that trainings with STEM disciplines enhance students' selfefficacy feelings. Similarly, Connolly, Lee, and Savoy (2018) found that STEM activities had a positive effect on student's self-efficacy. In general, it can be said that STEM disciplines have an effect on the solutions to daily life problems and students have roles in STEM disciplines. As a matter of fact, Herdem, and Ünal (2018) determined that STEM education activities had positive effects on the students' adoption of STEM disciplines and career awareness. In addition, Gülen (2018) and Gülen and Yaman (2019) found that STEM education had a positive effect on the solutions to everyday life problems.

In general, it was found out that the groups stated that a heavy load could be lifted by using a lever. What is more, it was observed that the design (engineering) of the leverage (technology) calculations such as number of partitions and force values were applied (mathematical) in the groups. According to this, even though 50 Newton were applied by using 11-segment (meter) leverage, it was determined that the second group members applied 33.33 Newton force with 16-segment (meter) leverage. Similarly, it was witnessed that the groups indicated that a heavy load could be lifted using a pulley. Along with that it was determined that the groups made calculations (mathematical) such as design (engineering), 
rope number and force values of the pulley (technology) to be used. According to this, 250 Newton were applied through using a 4-stringed pulley, whereas the fourth group members applied 125 (166.67) Newton with a 6-stringed pulley. Only the fourth group of members detected a mathematical calculation error. As can be seen, students successfully fulfilled their roles in STEM disciplines. These results come from the recognition of these disciplines. In that sense, Tai et al. (2006) pointed out that secondary school students are more likely to earn degrees in STEM if they are interested in a science career and believe that the knowledge, they have pertaining to science will be useful in their future. Here, it is seen that students' recognition of science affects this result. In another study, Rosenhal, London, Levy, and Lobel (201) mention the increase in the sense of belonging to the profession by the women's reading year, the harmony of identity with the profession and the support they give to their environment relating these to STEM training. Here, it is seen that the individual's recognition of occupation and profession is positively correlated with commitment to the profession. This situation positively affects the use of STEM disciplines in the courses and the students' role of these disciplines paves the way to connecting professional groups. Subramaniam, Ahn, Fleischmann, and Druin (2012) argued that school libraries should be used effectively in order to help students establish their identities for STEM disciplines. The result here is about providing students with more environments enabling the recognition of STEM disciplines. In fact, studies on these issues should be intensified. Scholars like Osborne, Simon, and Collins (2003) pinpointed that few studies were conducted in the context of science lessons in order to determine the nature and style of teaching and activities that attracted the attention of students. Also, Maltese and Tai (2011) diagnosed that middle school students were not aware of their career options. As it is understood in this study, in order for students to recognize STEM disciplines and to direct the knowledge of these disciplines to their professions, it is necessary to conduct studies in which they can acquire the roles of STEM disciplines. Finally, Breiner, Harkness, Johnson, and Koehler (2012) detected that individuals who are not engaged in STEM education have negative thoughts about STEM and their professions. In order for an overall elaboration of the roles of STEM disciplines as well as the preference for the occupations in this field, STEM education practices need to be expanded via differentiations at the role level.

In light of the pre-post test results of the experimental and control groups, it could be articulated that there is no significant relationship between the experimental and control groups. Namely, there is no relationship between the control group students who are educated through the normal curriculum and the academic achievement of the experimental group students who are trained with STEM roles activities besides receiving "normal" education. Güven, Selvi, and Benzer (2018) found no significant difference between the scores of the groups in STEM training studies. The reasons for not having any relationship between the academic achievement of the groups could be linked to the low number of questions in the achievement test and low number of participants (Büyüköztürk, 2009; Çepni, 2010). On the other hand, the number of individuals is very important in experimental studies. Herdem and Ünal (2018) and Cakir and Ozan (2018) Gülen and Yaman (2019) found that STEM activities boosted academic success. Furthermore, Çevik (2018) shared that both the academic achievement of the students and professional interest had a positive effect on STEM education.

\section{Conclusions and recommendations}

It was determined that STEM disciplines and STEM roles had a significant effect on the solutions to daily life problems. To be able to increase the rate of using STEM disciplines 
in daily life problems and augment the rate of individuals acquiring the roles of STEM disciplines, resorting to STEM disciplines in science courses should become more frequent.

It was found that the participants were able to lift the stone in the middle of the field by using a lever and move the elephant by using a pulley depending on the number of ropes. It was determined that the participants lifted a lot of load by applying less force. In order for individuals to solve such problems more easily, it is necessary to focus on daily life problems. STEM roles seemed to have no effect on increasing academic achievement compared to getting education through the existing curriculum. In this way, it is necessary to pay attention to the number of students in experimental studies.

\section{References:}

Arık, S., \& Y1lmaz, M. (2017). Attitudes of science teachers towards environmental problems and their metaphorical perceptions for environmental pollution. Kastamonu Education Journal, 25(3), 1147-1164.

Breiner, J. M., Harkness, S. S., Johnson, C. C., \& Koehler, C. M. (2012). What is STEM? A discussion about conceptions of STEM in education and partnerships. School Science and Mathematics, 112 (1), 3-11. https://doi.org/10.1111/j.1949-8594.2011.00109.x

Büyüköztürk, Ş. (2009). Manual of data analysis for social sciences (Turkish edition). Ankara: Pegem Academy.

Cakir, R., \& Ozan, C. E. (2018). STEM activities on 7th grade students' academic achievements, reflective thinking skills and motivation. Gazi University Journal of Gazi Faculty of Education, 38 (3), 1077-1100.

Carnevale, A. P., Smith, N., \& Melton, M. (2011). STEM: Science technology engineering mathematics. Washington: Georgetown University Center on Education and the Workforce.

Çepni, S. (2010). Introduction to research and project work (Turkish edition). Trabzon: Celepler Printing.

Çepni, S. (2018). STEM training from theory to practice (Turkish edition). Ankara: Pegem Academy.

Çevik, M. (2018). Impacts of the project based (PBL) science, technology, engineering and mathematics (STEM) education on academic achievement and career interests of vocational high school students. Pegem Journal of Education and Training, 8(2), 281306. DOI: 10.14527/pegegog.2018.012

Connolly, M. R., Lee, Y-G., \& Savoy, J. N. (2018). The effects of doctoral teaching development on early-career stem scholars' college teaching self-efficacy. Life Sciences Education, 17(1), 1-15. https://doi.org/10.1187/cbe.17-02-0039

Creswell, J.W. (2013). Qualitative research methods (Trans. Ed.: Whole, M., \& Demir, S.B.). Ankara: Political Publications Distribution.

Creswell, J.W. (2017). Introduction to mixed method research (Trans. Ed.: Sözbilir, M) Ankara: Pegem Akademi Publications.

Demirkuş, N. (2019). Important concepts in biology. http://www.biyolojiegitim.yyu.edu.tr/ders/kav.htm Accessed on 12.07.2019

Glesne, C. (2013). Introduction to qualitative research (Trans.Ed .: Ersoy, A., \&Yalcinoglu, $P$.). Ankara: Anı Publishing.

Gülen, S. \&Yaman, S. (2019). The effect of integration of STEM disciplines into Toulmin's argumentation model on students' academic achievement, reflective thinking, and psychomotor skills. Journal of Turkish Science Education, 16(2), 216-230. DOI: 10.12973/tused10276a 
Gülen, S., \&Yaman, S. (2018). Argumentation process and use of STEM disciplines in science lesson;focus group interview. YYU Journal of Education, 15(1), 11841211.http://dx.doi.org/10.23891/efdyyu.2018.101

Gülen, S. (2018). Determination the effect of STEM-integrated argumentation-based science learning approach in solving daily life problems. World Journal on Educational Technology: Current Issues, 10(4), 95-114.

Güven, Ç., Selvi, M. Benzer, S. (2018). Teaching applications' based on 7E learning model centered STEM activity effect on academic achievement. Journal of Social Sciences of Mus Alparslan University, 6, 73-80.

Herdem, K., \& Ünal, İ. (2018). Analysis of studies about STEM education: A meta-synthesis study. Journal of Educational Sciences, 48(48), 145-163. DOI: $10.15285 /$ maruaebd. 381417

Johnson, C. C. (2012). Implementation of STEM education policy: Challenges, progress, and lessons learned. School Science and Mathematics, 112(1), 45-55. https://doi.org/10.1111/j.1949-8594.2011.00110.x

Maltese, A. V., \& Tai, R. H. (2011). Pipeline persistence: Examining the association of educational experiences with earned degrees in STEM among U.S. students. Science Education, 95:877-907. https://doi.org/10.1002/sce.20441

Merriam, S. B. (2013). A guide for qualitative research design and implementation (Trans. Ed.: Turan, S.). Ankara: Nobel Publishing.

Metin, M. (2014). Scientific research methods in education from theory to practice. Ankara: Pegem Academy Publishing

Miles, B. M., \& Huberman, A. M. (1994). Qualitative data analysis (2nd ed.). London: Sage Publication.

Ministry of National Education (MoNE), (2018). Elementary and secondary school 3, 4, 5, 6, 7 and 8 grades science curriculum. Ankara: MoNE publications

Olson, S., \&Labov, J. (2014). STEM Learning is everywhere: Summary of convocation on building learning systems. California: National Academies Press

Ong, M., Smith, J. M., \& Ko, L. T. (2017). Counterspaces for women of color in STEM higher education: Marginal and central spaces for persistence and success. Journal of Research in Science Teaching, 55(2), 206-245.https://doi.org/10.1002/tea.21417

Osborne, J., Simon, S., \& Collins, S. (2003). Attitudes towards science: A review of the literature and its implications. International Journal of Science Education, 25(9), 1049-1079.

Roccas, S., \& Brewer, M. B. (2002). Social identity complexity. Personality and social psychology review, 6, 88-106.

Rosenhal, L., Londra, B., Levy, S. R., \&Lobel, M. (2011). The roles of perceived identity compatibility and social support for women in a single-sex STEM program at a coeducational university. Journal of Nonverbal Behavior, 65(9-10), 725-736.

Sanders, M. E. (2009). STEM, STEM education, STEMmania, the technology Teacher, December/January, 20-26.

Subramaniam, M. M., Ahn, J., Fleischmann, K. R., \& Druin, A. (2012). Reimagining the role of school libraries in STEM education: Creating hybrid spaces for exploration. The Library Quarterly, 82(2). 161-182. https://doi.org/10.1086/664578

Tai, R. T., Liu, C. Q., Maltese, A. V., \& Fan, X. T. (2006, May 26). Planning early for careers in science. Science, 312(5777), 1143-1144.

West, M. (2012). STEM education and the workplace. Office of the chief scientist occasional paper series, 4, 1-4.

Yıldırım, A. \&Şimşek, H. (2013). Qualitative research methods in the social sciences. Ankara: Seçkin Publishing. 